\title{
Comparative Study of Conventional and Quick Die Change Stamping Process: The Issue of Setup Time and Storage
}

\author{
Rudi Kurniawan Arief, Qomarotun Nurlaila and Armila

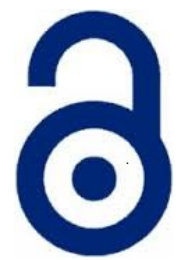 \\ Received: 16 September 2018 \\ Accepted: 22 October 2018 \\ Published: 01 December 2018 \\ Publisher: Deer Hill Publications \\ (C) 2018 The Author(s) \\ Creative Commons: CC BY 4.0
}

\begin{abstract}
Metal stamping industry has Quick Die Change (QDC) as a form of Single Minutes Exchange of Dies (SMED) as an efficient production technique where the implementation depends on operator's activities, clamping system, accessories type and position, etc. This QDC could apply to improve the process efficiency, control of inventory and reducing the cost. This research compared the traditional metal stamping process and QDC System (QDCS) of metal stamping. This research was using Focused Group Discussion (FCD), direct observation and experiments, conducted in a private metal stamping company in wider Jakarta region of Indonesia. It was observed that the QDCS significantly reduces setup time, storage space and the cost. The setup time and cost reduced to one third of the conventional and the requirement of storage decreased by $70 \%$. In addition, QDCS reduces the waste significantly.
\end{abstract}

Keywords. SMED, QDC, Process Efficiency, Lean Manufacturing

\section{INTRODUCTION}

In the field of manufacturing industry especially metal stamping industry, the Single Minute Exchange of Die (SMED) founded by Shigeo Shingo during 1950's is the most widely used [1]. SMED increased efficiency in metal stamping by moving the setup process of stamping die that usually held at the machine bed in outside area, which become a preset up process. Due to high production rate, product variability, short product's lifecycle and inventories, the SMED technique become a popular method in metal stamping industries [2]. Later, this SMED technique also developed to other field of industry outside metal stamping.

Today's trend required higher demand of product variation by the costumer. This has become a big problem for metal stamping company, since metal stamping required large quantity production to reduce the overall cost. Large product variation required frequent change of tools (die set) and low scale production than usual which make company to focus on process innovation [3]. The main focus of SMED is to eliminate wastes from tool setting activities by reducing the time less than 10 second [4]. In metal stamping industry, this SMED technique also called by Quick Die Change (QDC) with the concept of simplification of in-machine setup by the standardized activities and work sequence. Most of the QDC techniques associated with machine and tools accessories, operator's activities such as clearing area, clamping, setting, etc. [5], which reduces the waste and save $75 \%$ time and 50\% manpower [6].

\section{QUICK DIE CHANGE}

The SMED technique invented by Shigeo Shingo may increase production capacity up to $40 \%$ by making a clear arrangement of the production activities [1]. In 2002, a Japanese Fumio Yamaguchi developed a new system of QDC (QDCS) by modifying the die stamping die itself [7]. QDCS has become further step of SMED to reducing waste and

\section{R. K. Arief ${ }^{1} \otimes$, Q. Nurlaila ${ }^{2}$ and Armila $^{3}$}

Universitas Muhammadiyah Sumatera Barat, Padang

West Sumatera, Indonesia

E-mail: rudikarief@umsb.ac.id

2Universitas Riau Kepulauan, Batam

Kepri, Indonesia

E-mail: laila@ft.unrika.ac.id

${ }^{3}$ Universitas Muhammadiyah Sumatera Barat, Padang

West Sumatera, Indonesia

E-mail: armila@umsb.ac.id

Reference: Arief, R. K., Nurlaila, Q. and Armila (2018). Comparative Study of Conventional and Quick Die Change Stamping Process: The Issue of Setup Time and Storage. International Journal of Engineering Materials and Manufacture, 3(4), 216-223. 
decreasing company's expenses that modify the construction of metal stamping die. The concept of QDCS, in die construction point of view, is to separate main die or stamping function with the support function. Parts with die stamping function are grouping as one assembly named Quick Die Change Dies / QDCD and group of parts with support function as the other assembly named Quick Die Change Housing / QDCH as shown in Figure.1. In the construction of conventional die, supporting and main components construct as one big assembly as shown in Figure. 2. This cause higher cost to construct a die for a small component. With QDCS company only need to build the QDCD to be inserted into QDCH and QDCH may use for many of QDCD. This inserted and exchanging system of QDCS could save manufacturing cost for about 35\% [8].

\section{METHODOLOCY}

This research is to investigate the advantages termed as "efficiency" that might gain from the implementation of QDCS. Investigation will include the efficiency gained from setup time, storage area and the cost for all of these. Main data are collected from direct observation and interview. Activities held in a metal stamping company near Jakarta wider region. Focused Discussion Group attended by manager and supervisor from department of Engineering, quality control and production of designated company. Time consumed by the operators to setup the dies has been counted and compared. Dimension of dies and the storages has been measured. Those two parameters have been converted into parameter of cost based to Indonesian currency (Rupiah / IDR).

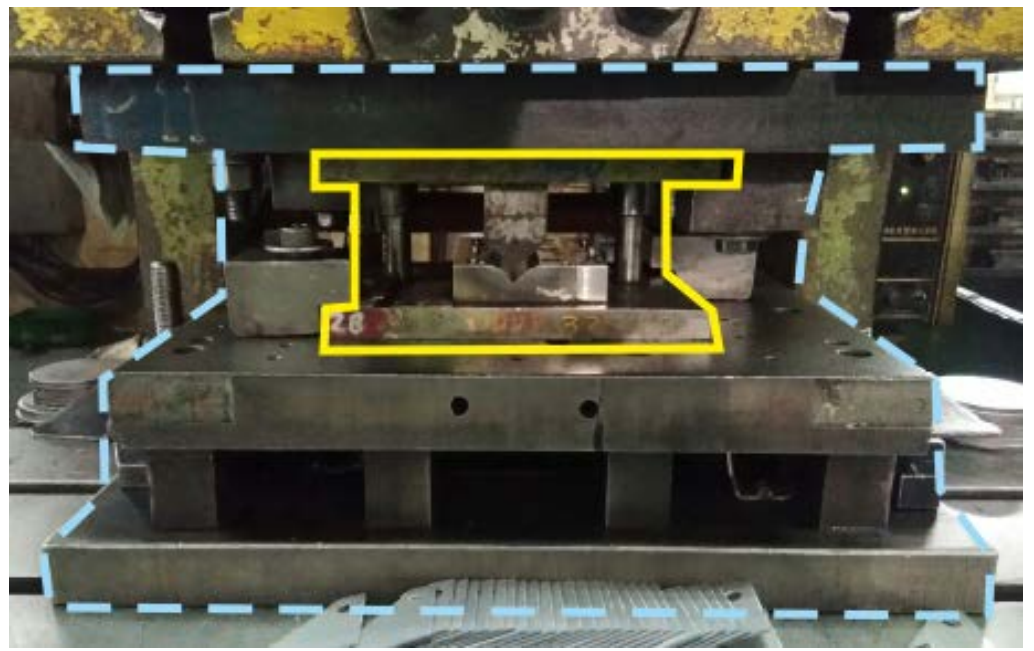

Figure 1: Construction of QDCS. Blue dashed line is showing the construction of QDCH and yellow full line show the construction of QDCD.

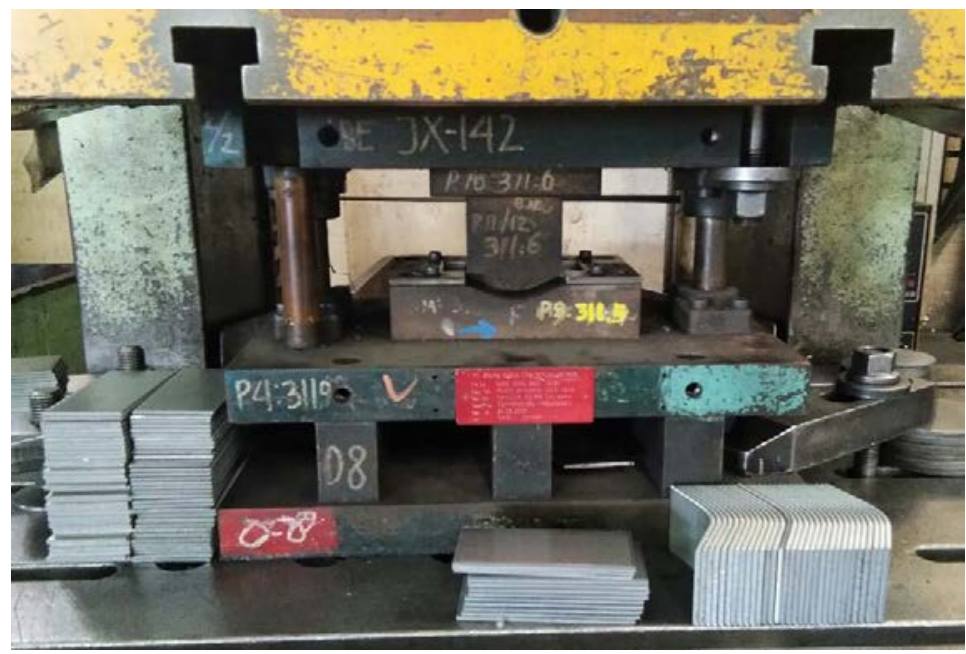

Figure 2: Construction of conventional die 


\section{ANALYSIS OF SETUP TIME EFFICIENCIES}

The QDCS is the combination of QDCD and QDCH where QDCD is very light in weight so it can be carried by hand, while conventional dies must be carried by lifting device. Observation will count the setup time from picking up dies from the storage, positioning on the table, machine's height setup (inching), clamping, unclamping and unloading out of the machine. These steps from each die construction have been compared.

\subsection{Setup Time of Conventional Die}

Time counted from the first operator picking up dies from storage in different room by forklift. Die operator then adjusted the position of dies according to applicable clamping groove. The machine height is adjusted to desired position and then operator start to clamps. Dies were unclamped after production process is finished and took by forklift operator to put back to storage area where located 10 meters away. Flow process shown by chart in Figure 3.

\subsection{Setup Time of QDCH}

QDCH must be setup before QDCD can be use. Setup time is similar to conventional die since QDCH has big construction as conventional die and placed in the same storage area. Setup process also similar to the conventional die.

\subsection{Setup Time of QDC}

QDCD as explained before will be placed inside of the $\mathrm{QDCH}$, so the observation condition is where the QDCH already installed. QDCD has been picked up from the storage that located two meters away, and could pick up directly by hand. QDCD then easily positioned inside the QDCH with help of guide rail provided. Inching did not take long time because initial inching already done by setup of $\mathrm{QDCH}$. Clamping devices have already been provided for quick clamping and unclamping activities. Setup and uninstall process is shown in Figure 4.

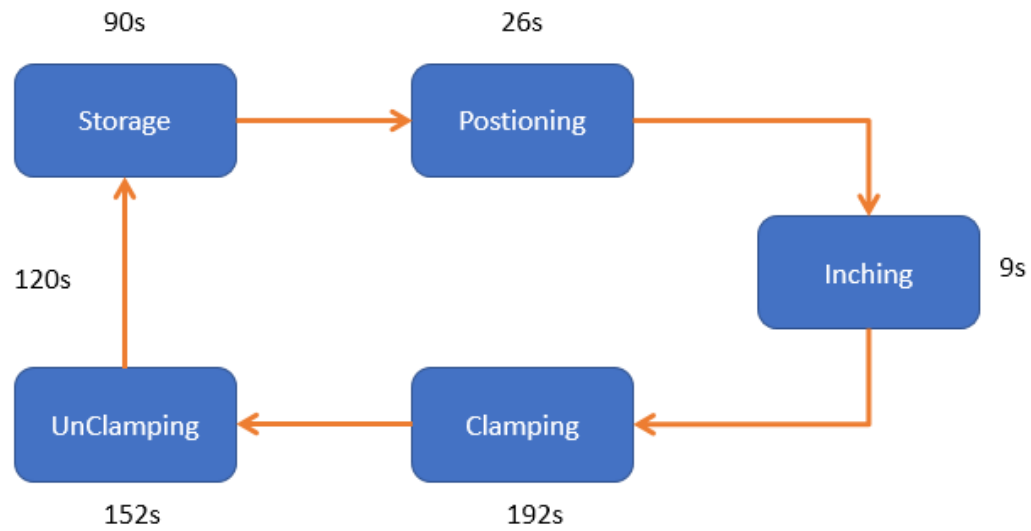

Figure 3: Process chart for conventional die setup

$13 \mathrm{~s}$

$5 s$

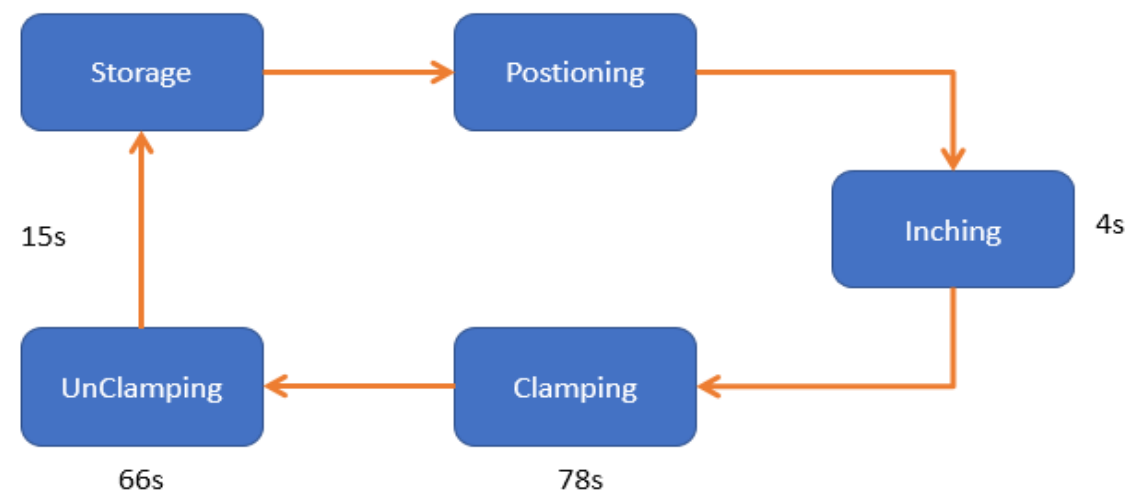

Figure 4: Process chart for QDCD setup 


\subsection{Setup Time Comparison}

Table 1 explained the comparison of setup time between two systems. From data presented in Figure 5, shown huge differences between those two dies construction. QDCD setup is $69 \%$ faster compared to conventional die. However, QDCD is depends to QDCH, so setup time of QDCH must be added in order to know real efficiencies. Data above shown that using one QDC is less efficient (-30.61\%) because combination setup time of QDCH and QDCD. However, after application of two QDCD that use directly after the first die, efficiency gap become wider. The increasing of gap percentages can be seen in Table 2 as well as in Figure 6.

Table 1: Comparison of setup time

\begin{tabular}{lccc}
\hline & Activities & QDCD $(s)$ & Conventional Die (s) \\
\hline Pickup dies & 13 & 90 \\
positioning & 5 & 26 \\
Inching & 4 & 9 \\
Clamping & 78 & 192 \\
Unclamps & 66 & 152 \\
Unload dies & & 15 & 120 \\
& Total Time & 181 & 589 \\
& & 3 Minutes & 9,8 Minutes \\
\hline
\end{tabular}

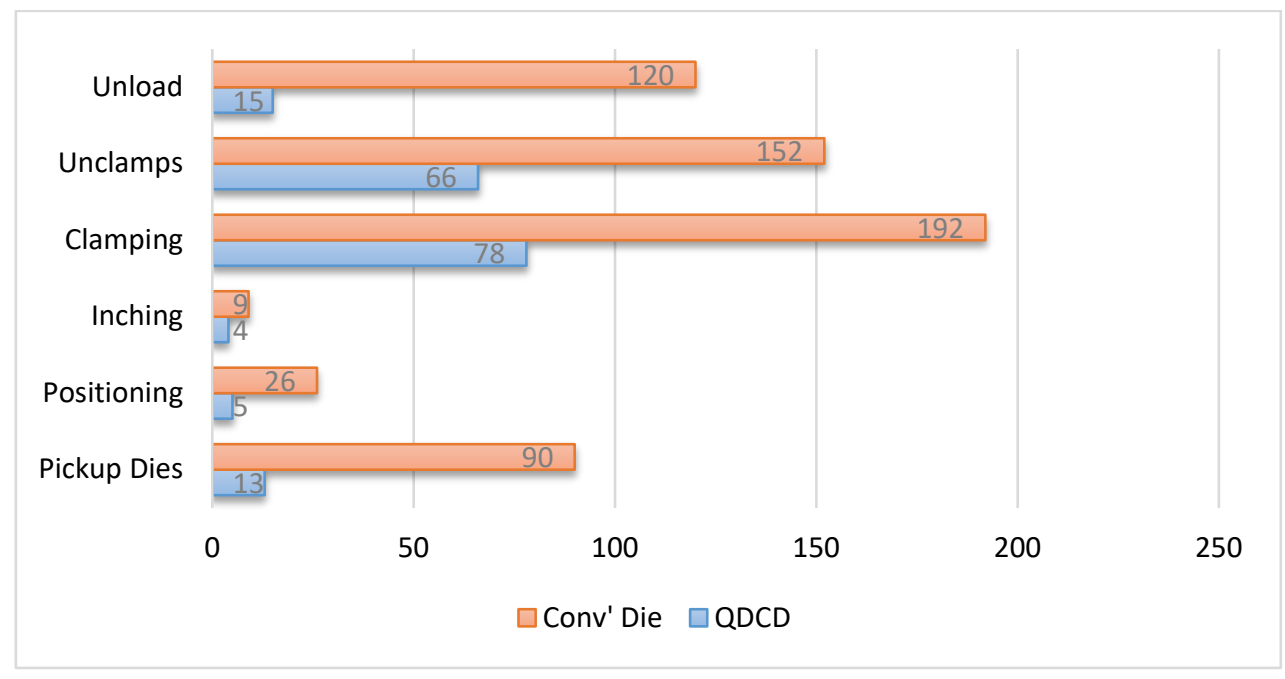

Figure 5: Setup time comparison chart

Table 2: Efficiencies comparison

\begin{tabular}{|c|c|c|c|}
\hline $\begin{array}{c}\text { Number of Die to be Installed } \\
\text { Sequentially }\end{array}$ & Conv' Die (s) & QDCS (s) & Efficiency Percentages QDCS to Conv' Die \\
\hline 1 & 9,8 & 12,8 & $-30,61 \%$ \\
\hline 2 & 19,6 & 15,8 & $19,39 \%$ \\
\hline 3 & 29,4 & 18,8 & $36,05 \%$ \\
\hline 4 & 39,2 & 21,8 & $44,39 \%$ \\
\hline 5 & 49,0 & 24,8 & $49,39 \%$ \\
\hline 8 & 78,4 & 33,8 & $56,89 \%$ \\
\hline 10 & 98,0 & 39,8 & $59,39 \%$ \\
\hline 15 & 147,0 & 54,8 & $62,72 \%$ \\
\hline 20 & 196,0 & 69,8 & $64,39 \%$ \\
\hline
\end{tabular}




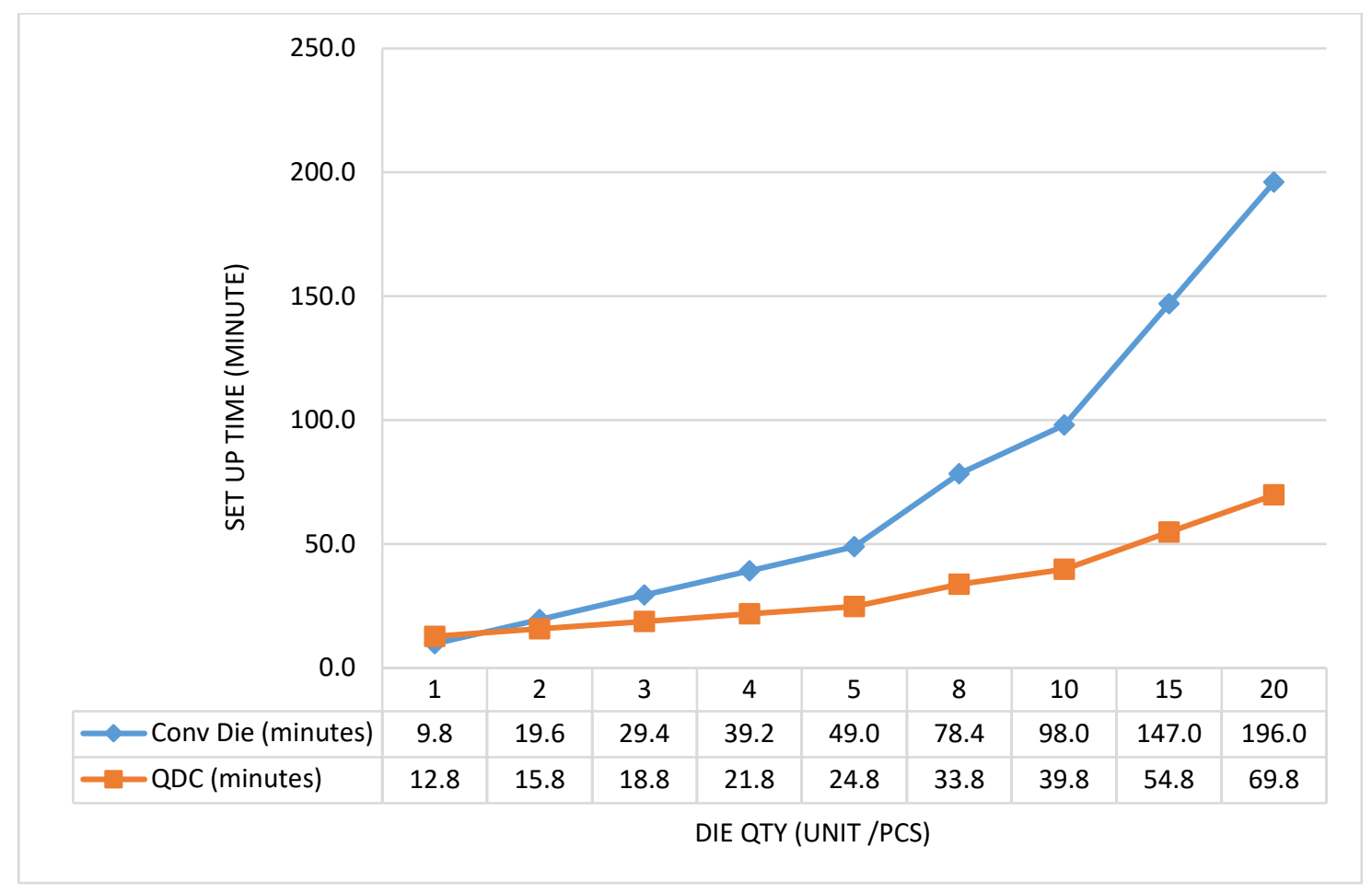

Figure 6: Efficiencies comparison' chart, comparing setup time required for some number of dies.

\subsection{Setup Time Cost Comparison}

Setup process from the observation above then analysed into cost parameters. Manpower and machine rate will be calculated as the parameter of direct cost. Cost of electricity, maintenance, administration, factory rent, etc. will be ignorance. Since observation conducted in Indonesia the cost calculation will using IDR by assuming 1 USD $=14.000$ IDR. Observed stamping process was conducted with 80 Tons manual stamping machine, operated by one person. Observed company is located in Kota Bekasi, an industrial city near Jakarta. Only net wage will be calculated outside any allowance might offer by the company to their labour. Current minimum labour wages (UMR) for manufacturing industry in this area in 2018 is 3.900.000 IDR with 26 days of working per month.

$$
\begin{aligned}
\mathrm{Lc} & =\text { UMR / } 26 \text { days/ 8hour/ 60minutes } \\
& =3.900 .000 / 26 / 8 / 60 \\
& =312,5 \mathrm{IDR} / \text { minute. }
\end{aligned}
$$

Labour cost per minute is 312,5 IDR.

From Table 1, we have data of setup time for QDCS is 3 minutes (St1) and conventional die is 9,8 minutes (St2). Labour cost to performance the setup is Labour cost per minutes times setup time.

$$
\begin{aligned}
\mathrm{Scl} & =\mathrm{St} 1 \times \mathrm{Lc} \\
& =3 \mathrm{~min} \times 312,5 \mathrm{IDR} \\
& =937,5 \mathrm{IDR} . \\
\mathrm{Sc} 2 & =S \mathrm{St} \times \mathrm{Lc} \\
& =9,8 \mathrm{~min} \times 312,5 \mathrm{IDR} \\
& =3.062,5 \mathrm{IDR} . \\
\mathrm{Eg} & =S \mathrm{~S} 2-\mathrm{Sc} 1 \\
& =3.062,5-937,5 \\
& =2,125 \mathrm{IDR} .
\end{aligned}
$$

Where, $U M R=$ Current minimum labour wages, $L c=$ Labour cost (IDR/min), St1 = setup time for QDCS (minutes), $S t 1=$ Setup time conventional die (minutes), $S c 1=$ setup cost for QDCS (IDR), Sc2 = setup cost for conventional die (IDR), Eg= Efficiency gap (IDR). 
Machine rate for 80 Tons stamping machine is 170 IDR per stroke, machine can perform 360 stroke per hour or 6 stroke per minute.

$$
\begin{aligned}
\text { Spm } & =\text { Sph } / 60 \\
& =360 / 60 \\
& =6 \text { stroke } / \mathrm{min} . \\
\text { Mc1 } & =S t 1 \times \text { Spm } \\
& =3 \times 6 \\
& =18 \text { strokes. } \\
\text { Mf1 } & =\text { Mc1 } \times \text { Mr } \\
& =18 \times 170 \\
& =3.060 \mathrm{IDR} . \\
\text { Mc2 } & =S t 2 \times \text { Spm } \\
& =9,8 \times 6 \\
& =58,8 \text { strokes. } \\
\text { Mf2 } & =\text { Mc2 } 2 \text { Mr } \\
& =58,8 \times 170 \\
& =9.996 \mathrm{IDR} . \\
\text { Er } \quad & =100 \%-(100 \% \times(\text { Mf2/Mf1 })) \\
& =100 \%-(100 \% \times(3.060 / 9.996)) \\
& =100 \%-30,6 \% \\
& =69,4 \% .
\end{aligned}
$$

Where, $\mathrm{Sph}=$ Stroke per hour, $\mathrm{Spm}=$ Stroke per minute, $\mathrm{Mr}=$ Machine rate, $\mathrm{Mcl}=$ Machine cost for QDCS, $\mathrm{Mf1}=$ Machine fee for QDCS, Mc2 = Machine cost for Conventional, Mf2= Machine fee for Conventional, Er= Efficiency rate. Converting to machine rate QDCD setup cost is 3.060 IDR and conventional die 9.996 IDR. QDCD successfully reduced direct cost by $69,4 \%$ compared to conventional die. Summary of cost calculation is presented in Table 3 .

Table 3: Cost efficiencies comparison

\begin{tabular}{ccc}
\hline Parameters & QDCS & Conventional \\
\hline Manpower & 938 IDR & 3.063 IDR \\
Machine Rate & 3.060 IDR & 9.996 IDR \\
Total Cost & 3.998 IDR & 13.059 IDR \\
\hline
\end{tabular}

\section{ANALYSIS OF STORAGE EFFICIENCIES}

SMED technique not just increase productivity and reduce cost but also able to reducing inventories [2]. QDCD built with smaller size due to it's insertable function while $\mathrm{QDCH}$ is same in size but less height than the conventional die. The QDCH only require 1 unit for each stamping machine, so the quantity is very less and QDCD will be more because manufactured 1 unit for each process. The size of QDCD and QDCH is already standardized and conventional die will be analysed with minimum size that can be build. Analyses is doing by simulating the data taken accordingly to the situation in designated company that owned 80 units of QDCD, 5 units of QDCH and hundreds of conventional dies. Analysis conducted by simulating the storage for 80 unit of dies.

QDCD required 5 row and 16 column storages to store 80 units of die with total foot print consumed 1.680 meters (Figure 7). Conventional die needs 4 row and 20 column storages to store 80 units of die with total foot print 5.520 meters (Figure 8). Monthly factory space rent fee at designated company's location is 40.000 IDR /M. QDCD save rent fees 153.600 .000 IDR every month due to small storage area required. Comparing with conventional die, QDCS reduce cost for storage to 70\%; the details are shown in Table 4. 
Table 4: Storage comparison for 80 units QDCS and Conventional die

\begin{tabular}{|c|c|c|c|c|c|c|c|c|c|}
\hline A & B & $C$ & $\mathrm{D}$ & $E$ & $F$ & $G$ & $\mathrm{H}=\mathrm{F} \times \mathrm{G}$ & 1 & $\mathrm{~J}=\mathrm{H} \times \mathrm{I}$ \\
\hline \multirow[t]{2}{*}{$\begin{array}{l}\text { Die } \\
\text { Type }\end{array}$} & \multirow[t]{2}{*}{$\begin{array}{l}\text { Die Size } \\
(\mathrm{mm})\end{array}$} & \multirow[t]{2}{*}{$\begin{array}{l}\text { Space } \\
\text { required } \\
(\mathrm{mm})\end{array}$} & \multicolumn{2}{|c|}{$\begin{array}{c}\text { Storage Rack } \\
\text { (80 Dies) }\end{array}$} & \multicolumn{2}{|c|}{$\begin{array}{c}\text { Space } \\
\text { Dimension } \\
(\mathrm{mm})\end{array}$} & \multirow[t]{2}{*}{$\begin{array}{c}\text { Total } \\
\text { Space } \\
(\mathrm{M})\end{array}$} & \multirow[t]{2}{*}{$\begin{array}{l}\text { Rent pe } \\
\text { Meter } \\
\text { (IDR) }\end{array}$} & \multirow[t]{2}{*}{$\begin{array}{l}\text { Monthly Rent } \\
\text { Fee (IDR) }\end{array}$} \\
\hline & & & Row & Column & Width & Length & & & \\
\hline \multirow{3}{*}{ QDCD } & $250 x$ & $350 x$ & & & & & & & \\
\hline & $200 x$ & $300 x$ & 5 & 16 & 300 & 5.600 & 1.680 & 40.000 & 67.200 .000 \\
\hline & 150 & 250 & & & & & & & \\
\hline \multirow{2}{*}{$\begin{array}{l}\text { Con'v } \\
\text { Die }\end{array}$} & $500 x$ & $600 x$ & & & & & & & \\
\hline & $\begin{array}{l}360 x \\
300\end{array}$ & $\begin{array}{l}460 x \\
450\end{array}$ & 4 & 20 & 460 & 12.000 & 5.520 & 40.000 & 220.800 .000 \\
\hline
\end{tabular}

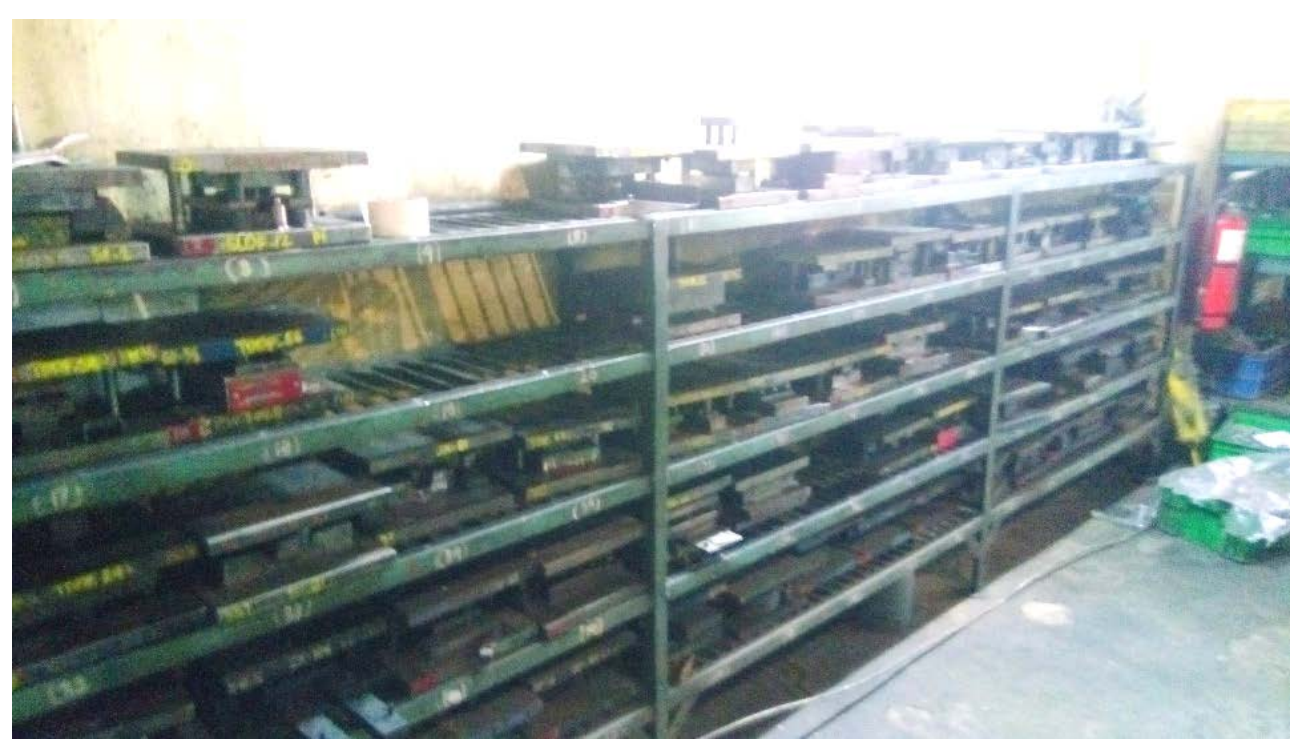

Figure 7: Storage for QDCD

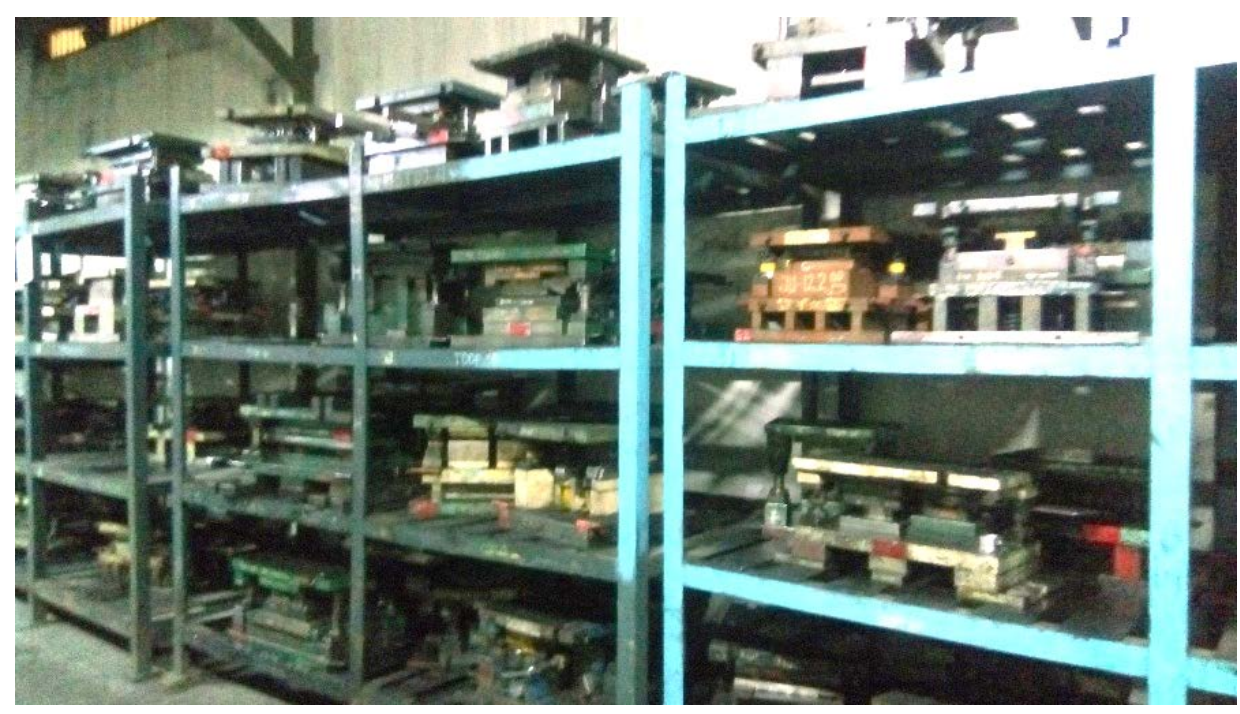

Figure 8: Storage for conventional die 


\section{CONCLUSIONS}

From the observation and analysis above QDCS could make efficiencies up to 70\% compares to conventional die. Amount of 153.000.000 IDR might be saved by the sleek design of QDCS from storages area, so some other wide storage spaces may be used for other productive activities. But company must pay attention for production arrangement where this QDCS must be employed sequentially for at least two QDCD, otherwise efficiently of process may decrease to $31 \%$. The QDCS must be employed sequentially in order to gain higher efficiency. With amount of efficiency achieved and plenty of money saved, metal stamping industry should be considering this system for their efficiency effort to produce more variable products with lower amount of quantity in a reasonable price.

\section{ACKNOWLEDGEMENT}

This research was funded by Ministry of Research, Technology and Higher Education Indonesia under Research Grant scheme of Penelitian Dosen Pemula 2018 (Project Number: 013/Kontrak-Penelitian/LPPM-UMSB/2018). The authors are grateful to the management team and employees of PT. Sanwa Presswork Indonesia where most of this research activities took place. This is the enhancement version of previous conference paper that has been submitted to CITES 2018 International Conference.

\section{REFERENCES}

1. Shingo, S. (1985). A Revolution in Manufacturing: The SMED System. Productivity Press, Oregon.

2. Yash, D. \& Sohani, N. (2012). Single Minute Exchange of Dies: Literature Review. International Journal of Lean Thinking, Volume 3, Issue 2.

3. Moreira, A. C., Pais, C. G. S., (2011). Single Minute Exchange of Die. A Case Study Implementation. Journal of Technology Management \& Innovation, Volume 6, Issue 1.

4. Abraham, Ganapathi K. N., Motwani, K. (2012). Setup Time Reduction through SMED Technique in a Stamping Production Line. SAS Tech Journal, Volume 11, Issue 2, Sep 2012.

5. Solehah, S (2013). Design and Development of SMED Quick Die Change Tools for Small Press Dies. University Malaysia Pahang, Malaysia.

6. Yamaguchi, F. (2013). Phillipine Metal Stamping Sector Study 2013. Jaoan Metals Industry Research and Development Center and Philipine Departemen of Science and Technology, Taguing City.

7. Arief, R. K. (2018). Time and Cost Efficiency Analysis of Quick Die Change System on Metal Stamping Industry. World Academy of Science, Engineering and Technology, International Journal of Industrial and Systems Engineering, Vol:12, No:2, 2018. dai:10.1999/1307-6892/10009095.

8. Suchy, I. (2006). Handbook of Die Design”. New York, McGraw-Hill.

9. Paquin, J. R., Crowley, R. E., (1986). “Die Design Fundamentals, 2nd Ed”, Industrial Press Inc., New York. 